\title{
LA PERSECUCIÓN DE LOS JESUITAS QUE NO JURARON LA CONSTITUCIÓN DE BAYONA EN LA CORRESPONDENCIA ENTRE LOS PP. JUAN JOSÉ CARRILLO Y MANUEL LUENGO (1808-1813)
}

\author{
Inmaculada FERNÁNDEZ ARRILLAGA \\ Universidad de Alicante
}

\begin{abstract}
Resumen
Durante su exilio en Italia, los jesuitas que fueron expulsados de España por Carlos III fueron requeridos a prestar el juramento de fidelidad prescrito en la Constitución de Bayona. La negativa de muchos de ellos a secundar tal demanda trajo consigo una serie de consecuencias que quedan reflejadas en la correspondencia mantenida entre dos de estos regulares expulsos, los PP. Luengo y Carrillo.
\end{abstract}

\begin{abstract}
During their exile in Italy the jesuits expelled by Charles III were required by the Constitution of Bayona to take oath of fidelity. The refusal of many to take such an oath brought a series on consequences which can be gleaned from the correspondence between the jesuits Luengo and Carrillo.
\end{abstract}

José Bonaparte fue proclamado rey de España el 25 de julio de 1808; en octubre de ese año se decretó que todos aquellos que recibieran pensión, procedente del Tesoro público, debían prestar el juramento de fidelidad prescrito en la Constitución de Bayona ${ }^{~}$. Negarse a dicho compromiso implicaba suspensión de todo beneficio económico procedente del Estado español. Entre los pensionados se encontraban cientos de regulares pertenecientes a la entonces extinta Compañía de Jesús. Estos jesuitas constituían una excepción ya que el modesto sueldo que cobraban no procedía del

1. El decreto puede leerse en el Diario de la expulsión de los jesuitas de España, escrito por el P. Manuel Luengo y custodiado en el Archivo Histórico de Loyola, Escritos de jesuitas del s. XVIII, baldas 4 y 5 , (a partir de aquí Diario), T. XLII, pp. 821-822. Aparece transcrito en VALBUENA, D.: «José Bonaparte y los ex jesuitas españoles», Razón y Fe, 22 (1809), p. 193. 
erario público, sino de la venta y rentas que proporcionaban las que fueran sus propiedades en España. Las reacciones de los exiliados ante la nueva resolución fueron variadas: unos firmaron el documento sin objeción alguna, pero hubo un grupo que se negó a hacerlo ${ }^{2}$. Las consecuencias no se harían esperar.

Entre los días 8 y 10 de diciembre de 1808, se intimaba el Decreto a los jesuitas que residían en Bolonia. Uno de ellos, el P. Juan José Carrillo, perteneciente a la Provincia de Castilla como su íntimo amigo, el P. Manuel Luengo, escribía a este diarista exponiéndole cómo se habían desarrollado los hechos en su ciudad de residencia, dando, con este motivo, inicio a una densa correspondencia entre los dos regulares, en la que Carrillo iría comentando a Luengo los avatares que pasaron los jesuitas residentes en Bolonia, a causa de su negativa a aceptar la Constitución de Bayona; mientras que, el P. Luengo, detenido en Roma por la misma causa, contaría a su amigo sus lances y los de otros jesuitas conocidos por ambos y en la misma disyuntiva. La primera carta que se conserva lleva fecha del 16 de diciembre de 1808 , cuando todavía estaba el P. Carrillo en Bolonia y en ella resaltaba la advertencia de: «aquellos que se negaran a firmar les sería retirada la pensión». Juan José Carrillo había solicitado leer la Constitución y ante la negativa a permitírselo argumentó que el desconocimiento del documento que iba a firmar le impedía estampar su nombre.

$\mathrm{Al}$ amanecer del día 29 de diciembre, fueron arrestados en sus casas de Bolonia, los veintidós jesuitas ${ }^{3}$ que no habían hecho el juramento al rey y, divididos en dos grupos, fueron llevados diez a la casa de los Padres de San Felipe de Neri y doce al convento de las Gracias, respectivamente. En el primero residían algunos jesuitas de la Provincia de Filipinas y, el segundo, estaba regentado por los Señores de la Misión de San Vicente. Desde este último, y ese mismo día, escribía el P. Carrillo al P. Luengo una carta breve comentándole la detención y explicándole las condiciones en que les habían alojado: «acuerdese usted de $\mathrm{Calvi}^{4}$ o de Bianchini», le decía a Luengo, refiriéndose a las limitadas comodidades de prisión y se despedía temiendo su traslado a Mantua. Efectivamente, el día 31 salían de la ciudad en la que habían vivido los últimos cuarenta años de su vida, desterrados hacia Mantua. Dejaban empleos de relevancia, uno de ellos había sido confesor del Arzobispo, otro de las teresianas de Bo-

2. De todos los exjesuitas españoles residentes en Roma, juró el $45 \%$ y el $55 \%$ se negó a prestar dicho juramento. Estos últimos estuvieron cerca de un año sin percibir la pensión real. Según OLAECHEA, R.: «El Cardenal Lorenzana y los ex jesuitas (Arevalo, Masdeu, Luengo, Bolgeni). Cartas de Arévalo a Lorenzana, 1793-1796», Archivum Historicum Societatis Iuesu, LI, (1982), p. 135(208).

3. Al final de este artículo aparece una pequeña reseña biográfica de cada uno de estos jesuitas que fueron llevados a Mantua.

4. En 1768 los jesuitas españoles hicieron escala forzosa en Córcega mientras esperaban poder entrar a los Estados Pontificios, ese mismo año y en esa isla nacía José Bonaparte. Sobre la estancia de los jesuitas en Córcega véase: MARTíNEZ GOMIS, M.: «Los problemas económicos y de habitación de los jesuitas españoles exiliados en Córcega (1767-1768), Disidencias y exilios en la España Moderna, Actas de la IV Reunión Científica de la Asociación Española de Historia Moderna, Alicante, 27-30 mayo, 1996, Universidad de Alicante-C.A.M., Alicante, 1997, pp. 679-690. 
lonia, algunos, profesores de hijos de personas influyentes en la urbe y varios confesaban en las iglesias y hospitales de la ciudad. Antes de salir, de mano del P. Grasi, jesuita italiano, y por orden del P. Pignatelli, recibió Juan José Carrillo ciento cuarenta y cinco pesos para ayuda en un viaje que no les llevaría más de dos o tres días.

Por su parte, y con el alarmismo que, tan a menudo, caracteriza a Luengo, afirmaba éste que en Roma, el 22 de enero los franceses comenzaron a perseguir a aquellos jesuitas españoles que no habían realizado el juramento al rey Josés ${ }^{5}$, iban a buscarles a sus casas y allí mismo les arrestaban, si no les localizaban en sus residencias se les podía detener por la calle o donde se les descubriera. Al convento de San Ildefonso lugar de residencia del P. Luengo, llegó el arresto ese mismo día a las ocho de la mañana, mientras él oficiaba misa. Les llevaron al despacho del comandante francés de la plaza, en el palacio del príncipe Colonna, allí coincidieron con otros españoles entre los que se encontraban diez jesuitas, la sentencia por su negativa al juramento fue leída al grupo: se les dictaba que eligiesen un convento de Roma donde permanecerían recluidos en grupos de seis o siete y con soldado de guardia. La casa de San Ildefonso, se aceptó como prisión, agregándose a los tres que ya la habitaban otros cinco $^{6}$. El resto se repartió entre la cárcel de San Romualdo, en la propia habitación de Sebastián Pascual, Agente del Cardenal Arzobispo de Toledo en Roma, que había sido arrestado con anterioridad y en cuya compañía se acomodaron cuatro jesuitas españoles; en el Gesú encerraron a unos treinta y en la de San Cosme y San Damián, quedaron cinco sacerdotes mejicanos.

Su actitud fue minoritaria, ya que la mayoría de los expulsos aceptaron el juramento. Según Carrillo, la causa por la que habían firmado los otros españoles se fundaba, más que en el acuerdo, en la precipitación con que se había hecho el juramento, el poco tiempo que habían tenido para pensarlo y las coacciones recibidas. De la misma opinión era el P. Luengo:

«...con la esperanza de que les den alguna cosa para no morirse de hambre, con el temor de prisiones, destierros o de deportaciones, conque se les amenaza y con las doctrinas obvias en todos los autores de que es licito hacer Juramento de fidelidad a un usurpador y a un tyrano y aun con los exemplares de los Juramentos aprovados por el Papa para los Obispos en los Concordatos con Francia y con el Reyno de Italia, casi todos los jesuitas españoles del Reyno de Italia han hecho también el Juramento al Rey Joseph Napoleon.... ${ }^{7}$

5. Véase: MERCADER RIBA, J.: José Bonaparte rey de España - 1808-1813: estructura del Estado español bonapartista, CSIC, Madrid, 1984. Especialmente el capítulo XIII. «Política eclesiástica», pp. 453-498.

6. Se unieron a la casa-prisión Juan Manuel Serrano, de la Provincia de Méjico; Ramón Diosdado y Santiago Gazoz de la de Toledo, junto a Diego de la Fuente y el coadjutor Juan Ferragut de la provincia castellana a la que habría que sumar a Ignacio Guerra y a Luengo, lo que completaba los siete jesuitas retenidos en San Ildefonso. Les acompañaba otro español, un pintor apellidado Acuña. LUENGO, M.: Diario, T. 43, p. 84.

7. LUENGO, M.: Diario..., T. XLIII, p. 11. 
El 2 de febrero de 1809, desde Mantua, dirigía el P. Carrillo otra carta a su amigo Luengo en Roma. En ella le informaba de su establecimiento en el Palacio Episcopal, donde vivían en comunidad con los seminaristas, pagando con ellos su manutención y con permiso para salir de la casa, aunque no de la ciudad. Quince de estos jesuitas habían pertenecido a la Provincia de Castilla ${ }^{8}$, cuatro a la de Méjico ${ }^{9}$, dos a la de Aragón ${ }^{10}$ y uno a la Provincia andaluza ${ }^{11}$. En cuanto a los jesuitas que residían en Orvieto parecían a salvo de todas estas inquietudes ya que el comandante de Viterbo había enviado al gobernador de Orvieto el edicto para su puesta en práctica y publicación, pero éste no lo hizo, argumentando que no conocía español alguno en su jurisdicción y, por lo tanto, que resultaba de todo punto innecesario.

En esa misma fecha, comentaba Carrillo a Luengo los rumores que les habían llegado sobre una disertación del P. Perotes ${ }^{12}$ en la que pretendía probar que el juramento se podía y se debía efectuar por los jesuitas, y con el mismo fin había escrito la suya otro jesuita, Agustín Puchol, al que se referían con el apodo de «el gordiflón» ${ }^{13}$. La primera no la habían conseguido, aunque la buscaban, pero la de Puchol les había llegado de Bolonia; para Carrillo la argumentación resultaba un tanto mezquina, ya que la únicạ conclusión que se sacaba era que había que obedecer a los soberanos «assi a bulto». Aseguraba también que, de no estar ya ciego, daba por seguro que Iturriaga ${ }^{14}$ escribiría la suya.

Las cartas seguían sucediéndose con regularidad semanal y el retraso en el recibo era habitual, llegando a demorarse más de diez días, cuando lo usual era que llegasen en cuatro o cinco. Esas tardanzas tenían para el P. Luengo una «inequívoca expli-

8. Se trataba de Antonio Roza, Martín Ostiz, Domingo Zuloaga, Manuel Miliá, Luis Sanvianes, Hermenegildo Amoedo, Pedro Rodríguez, Joaquín Campra, Juan Urteaga, Pedro Cordón, Isidro Arevalo, Vicente Calvo, Luis García, Francisco Javier Bouzas y Juan José Carrillo.

9. Félix Sebastián, José Corcines, José Antonio Encinas y F. Carrera.

10. Mariano Arascot y Salvador Cea

11. Joaquín Suers

12. Sobre el P. Francisco Javier Perotes véase: Batllori, M.: «La cultura hispano-italiana de los jesuitas expulsos (1767-1814), Ed. Gredos, Madrid, 1966. De este sacerdote, perteneciente a la Provincia de Castilla, conservaba Luengo, en su Colección de Papeles Varios, una apología de los jesuitas rusos, T. 7, p. 171, otra del P. Abad Cesáreo Pozzi, T. 12, p. 159, y su Historia del Jansenismo, T. 25, pp. 249-261.

13. Cuando salió de España, Agustín Puchol era estudiante del Colegio de Urgel, Provincia de Aragón. Había nacido en Vinaroz el 3 de octubre de 1743 y era jesuita desde el 31 de mayo de 1761. Embarcado en Salou el 1 de mayo de 1767 en la Saetía «Nuestra Señora del Buen Viaje», residió en Ferrara en 1771. El último trimestre de 1773 vivía en Ferrara, donde recibió 375 rls. de gratificación con la pensión; en A.G.S., Dirección General del Tesoro, Inventario 27, Leg. 1. Agradecemos estos datos al profesor Giménez López.

14. El P. Iturriaga era íntimo amigo del P. Manuel Luengo, de ahí que éste último refiera muchas noticias sobre las aventuras que tuvo que padecer el jesuita mejicano a la hora de intentar publicar sus obras. Realizó el juramento de fidelidad a José Bonaparte y a la Constitución de Bayona en diciembre de 1808 en Bolonia y, posteriormente, recibiría por su labor teológica un elogio de Pío VI. FERNÁNDEZ ARRILLAGA, I.: «El exilio de un jesuita mejicano en Italia y las impugnaciones que recibió su crítica teológica» Congreso Internacional ' 400 años de los jesuitas en Córdoba, Universidad Nacional de Córdoba, Argentina, septiembre de 1999. 
cación»; se trataba, en sus palabras, de una junta constituida en Bolonia, por orden del gobierno francés y formada por personas conocedoras de distintas lenguas, encargada de leer todas las cartas que se dirigían de Roma a Mantua y viceversa. Este convencimiento de que las misivas eran revisadas por los comisarios franceses, hacía que los jesuitas intercambiasen sus notas con referencias a vivencias comunes y con gran precaución; temerosos, como estaban, de esas posibles represalias que creían acecharles por doquier. Eso no fue óbice para que su correo fuera fluido y continuo durante años, perdiéndose sólo una misiva del P. Carrillo en la que comentaba sucesos relativos a la guerra en España fechada el 24 de julio de $1810^{\text {is }}$. Eso sí, la mayoría de las cartas del P. Luengo llegaban al P. Carrillo abiertas, especialmente las de los años 1812 y 1813. Los presos en Mantua, no se cansaban de agradecer las cartas del P. Luengo, ya que además de su extensión, a veces, les adjuntaba copia de su famoso Diario. Sobre este escrito el P. Carrillo tenía gran consideración:

«Me acuerdo que mas de una vez le dixe a usted a boca quan util, estimado y buscado seria despues de nuestros dias su exactisimo y menudisimo Diario con todos los documentos pertenecientes a los sucesos y a la historia interessante de tantos años» ${ }^{16}$.

Por entonces el P. Luengo ya había escrito cuarenta y dos extensísimos volúmenes de su Diario, escribía una media de veinte páginas semanales en su dietario, ampliaba su Colección copiando, incansable, los decretos, cartas y todo papel que consideraba sugestivo, mantenía correspondencia con jesuitas de Ferrara, Módena, Orvieto y los de Mantua y también con España. De dónde sacaba el P. Luengo tiempo y fuerzas para escribir tal cantidad de papeles, sin abandonar sus largas caminatas y sus casi diarias entrevistas con algún otro expulso en el Gesu para que le mantuviera informado, continuará siendo para nosotros causa de indescriptible asombro.

A los jesuitas de Mantua, que se negaron a jurar, poco les importaba que el rey José tuviera o no derecho al trono español, pues toda la dificultad la centraban en el compromiso a obedecer la Constitución de Bayona; en palabras del P. Carrillo: «lo que principalmente nos arredraba [a la hora de firmar el juramento] era la constitución que ningún catholico capaz de examinarla podía jurar». Luengo tenía opinión semejante: «era totalmente contraria a las prerrogativas y libertad de la Iglesia», afirmaciones que les valieron, una vez más, ser tachados de obstinados y defensores de ese espíritu de partido que caracterizó a la Sociedad de Jesús, en este caso concentrado en una reducida camarilla que representaba su más incorrupta esencia. El P. Pedro Cordón escribía, a través del P. Luengo, una carta a Luisa Jacomelli, adepta y protectora de los exjesuitas, en la que también explicaba la causa que les había movido a no firmar el juramento:

15. «Nueva prueba, aunque no necesaria, siendo cosa cierta y casi pública, de que en Bolonia, por donde pasan todos los correos, hai una Junta de diez o doce sugetos destinada a leer todas las cartas, que quieran de todos los Correos de todas partes y hacia todos lados», LUENGO; M.: Diario, T. XLIV, p. 664 .

16. Carrillo a Luengo, Mantua, 16 de abril de 1809. 
"Se trata de una constitución que establece libertad de prensa, y de tribunales, es decir el despacho del demonio, donde hasta el ministerio del culto depende del gobierno»"

El primer proyecto del Estatuto de Bayona, en su epígrafe VII titulado Culto, proponía seis artículos: el primero aceptaba la religión Católica Apostólica y Romana como único culto tolerado en el país, en el segundo se abolía la Inquisición, el siguiente confirmaba a los monjes de las órdenes religiosas existentes en España, y el cuarto prohibía recibir novicios a todas aquellas órdenes que no hubieran sido reducidas a la mitad de su número. Los otros dos artículos gestionaban las temporalidades derivadas de la reducción de las órdenes y de la supresión de la Inquisición. Al ordenar la restricción del número de profesiones para reducir las órdenes religiosas, se hacía eco Napoleón de un problema realmente existente, sobre todo en su aspecto económico ${ }^{18}$. No podemos pensar que esta fuera, únicamente, la causa que llevó a ese reducido número de jesuitas en el exilio a negarse a aceptar el estatuto. Su planteamiento era más político que reivindicativo e iba más dirigido al fondo de lo que significaba la constitución, como reglamento francés que la originaba, que el modo en que se pudiera articular; para este colectivo tan conservador resultaba inaceptable que el Estado dirimiera asuntos religiosos que les parecía de exclusiva incumbencia pontificia e intentaban con su actitud crear un estado de opinión refractario a cualquier tipo de avance reformista. De hecho, cuando se les presentó el segundo estatuto, en cuyo articulado no figuraban ningunas de las cláusulas referidas, exceptuando la aceptación de la religión católica como única del Estado, tampoco lo firmaron.

El P. Luengo añadía que la legitimidad del Estatuto y del monarca se fundaba en «mentiras, traiciones y en injurias manifiestas sin una sombra de derecho ni suya, ni de su hermano Napoleon» ${ }^{19}$, de ahí la ilegalidad de obligar a los españoles a reconocer un rey y una constitución «inaceptables». Pero todavía señalaba dos circunstancias que hacía aún más inadmisible el juramento para los jesuitas españoles. La primera era que ellos no debían ser considerados por el rey como españoles ya que, durante cuarenta años, habían tenido que sufrir destierro en Italia, soportando calificativos como expatriados y desnaturalizados que aparecían en la Pragmática Sanción de su destierro. Los ministros de Carlos III habían afirmado que la patria y el país natural de los seguidores de la Sociedad de san Ignacio era el estado del Papa, por lo que el rey no debería considerarlos súbditos suyos. Pero si el argumento era que se pedía juramento a los que se les otorgaba pensión, el P. Luengo recordaba que ésta no provenía de fondos del erario, sino de la venta de los bienes y haciendas de los Colegios que los jesuitas habían tenido que abandonar al ser expulsados de España por Carlos III.

Otros expulsos, que sí firmaron, al conocer que el P. Carrillo y otros habían sido detenidos por su actitud, le escribieron incrédulos y preguntando qué les había llevado a dar tal paso, pues no descubrían razón alguna en un juramento como aquel para

17. Carta del P. Pedro Cordón a Dña. Luisa Jacomelli, 9 de julio de 1809.

18. SANZ CID, Carlos: Constitución de Bayona, Ed. Reus, Madrid, 1922, p. 191 y ss.

19. LUENGO, M.: Diario, T. XLII, p. 768. 
no aceptarlo. Algunos de estos jurados, que se ponían en contacto con los presos, vivían en Crémona e insistían en recibir explicaciones; más tarde algunos jurados pertenecientes a la Provincia de Aragón, que residían en Mantua y solían visitar a sus hermanos, les fueron hechas las mismas cuestiones. En estos casos, el P. Carrillo declaraba que como habían jurado por desconocimiento y de buena fe era recomendable esquivar el asunto para no ofenderlos. Actitud difícil de entender, si tenemos en cuenta que el juramento, en muchos casos, se pidió en más de una ocasión, habiendo casos de jesuitas que juraron en la primera solicitud, pero que se negaron a hacerlo en las posteriores. De hecho, el P. Luengo, dedicó parte de su tiempo en hacer proselitismo entre los jurados para que, si volvían a pedirles su firma, se negaran a estamparla. Por su parte el P. Carrillo estaba seguro de que el ejemplo de Iturriaga haría gran fuerza en otros jurados ${ }^{20}$. Se refería a la justificación que dio el jesuita mejicano cuando le intimaron por segunda vez el juramento; en aquella ocasión dijo que ya habían firmado una constitución y que, si existía una nueva, debían antes conocer su contenido, persistieron en esa actitud y fueron encarcelados en Bolonia. En carta de 26 de febrero de 1809 el P. Carrillo relataba algunas novedades sufridas y, un mes más tarde, el P. Luengo las escribía en su Diario: «a los de Mantua se les había intimado el orden de pasar desde el Palacio del Obispo, en que estaban con libertad de salir a decir misa, a un convento suprimido de Monjas agustinas de san Bernabé que había servido de cuartel y donde se les priva de toda libertad». La causa para ese traslado, decía el P. Carrillo, que se debía a que se esperaba un cardenal deportado que querían poner en el obispado. De todas formas los rumores sobre traslados para los no jurados fueron continuos, el P. Luengo, había oído que serían llevados desde Roma a Mantua, a los que vivían en Mantua se les dijo, a finales de abril, que serían llevados a Francia, etc.

Uno de los temores para los jesuitas no jurados era la cuestión económica, ya que pesaba la amenaza de no recibir pensión como castigo. Pero además de las ayudas privadas (José Pignatelli ${ }^{21}$ entregó a Luengo cuatro pesos duros a cada uno de los que estaban retenidos en Roma, para ayuda de sus gastos), a los presos de Mantua se les pagaba una pensión de ocho reales semanales y por adelantado, además de las limosnas de particulares que les permitían algún desahogo. Además, a mediados de marzo de 1809, el gobierno de esa ciudad se preocupó de sacar fondos del arca de galeotes para ayudar a los padres, ante el riesgo de que faltara dinero para su manutención, como de hecho escasearía meses más tarde, cuando el riesgo de invasión por los alemanes hizo que se les retirara la guardia a los presos y que se les disminuyera la pensión.

A mediados de abril Mantua se quedó sin tropa, destinada a Verona para luchar contra el emperador de Alemania, de ahí que, a partir de ese momento, quedaran sin

20. Carrillo a Luengo, 9 de abril de 1809.

21. Véase: MARCH, José M.: El restaurador de la Compañia de Jesús, beato José Pignatelli y su tiempo, Imprenta Revista «Ibérica», Barcelona, 1935. 
custodia alguna, encerrados bajo su propia palabra. El P. Carrillo pedía al P. Luengo licencia papal para poner el Santísimo Sacramento en su capilla de la cárcel, permiso que le gestionó y se pudo poner en práctica en junio. Estaban contentos, dedicados a sus devociones, «más sanos que en Bolonia» y respetados por el pueblo. Carrillo contaba una anécdota, divertido y emocionado, a su amigo en la que aseguraba que las gentes, como no estaban acostumbradas a ver jesuitas, les daban toda clase de títulos: «uno que buscaba a Cordón, me preguntó por el P. Prior de los jesuitas. Otro buscaba a Arévalo y me preguntó por el Sr. Tesorero. Otro me preguntó por Encinas con el título de Intendente del vino [...] y es un gusto oir los títulos que dan a los que tienen el manejo ${ }^{22}$. Posiblemente, este relajo fuera el causante de sospechosas similitudes que encontraba el jesuita entre los acontecimientos ocurridos en Aranjuez, en marzo de 1808, con los que motivaron la caída de Esquilache en el Madrid de 1766. el P. Carrillo, que durante aquellos motines se encontraba en Rioseco, ya profetizó al P. Blanco:

«Vera usted como nos achacan a nosotros [se refería a los jesuitas] este tumulto. Por abril del año siguiente hervian los caminos de España de Jesuitas que iban a embarcarse en diferentes puertos para ser deportados, y en el mismo mes y por los mismos días del año 1809 atravessaba aquellos mismos caminos toda la casa real para expatriarse... Muchas cosas son casuales para nosotros los hombres, pero ninguna lo es para Dios» ${ }^{2: 3}$

En junio Carrillo felicitaba a Luengo por la libertad casi total de la que ya gozaban los jesuitas en Roma, mientras que los de Mantua contaban ya con cinco meses de arresto, y con el agravante de haber sido desterrados de la ciudad que les acogía, Bolonia. Comenzaba a quejarse de la mella que estaba dejando sentirse en el estado físico de los presos su encierro, ya que con el calor habían empezado a aparecer molestias que se complicarían a lo largo del verano. Mantua está situada en una baja llanura pantanosa de la Lombardía y rodeada por tres lagos que alimentan las aguas del río Mincio. Así es fácil entender que a la llegada de la estación estival la insalubridad amenazara a sus habitantes, los que podían abandonaban la ciudad para beneficiarse de los aires más higiénicos de la campiña, pero los que quedaban solían padecer fuertes fiebres ${ }^{24}$. Este fue el caso de los prisioneros jesuitas. Las temidas tercianas comenzaron atacando a comienzos del verano, siendo el primer contagiado el P. Encinas que, aunque superaba los setenta años, había gozado de excelente salud hasta entonces. Después las padecieron el P. Juan Urteaga y Hermenegildo Amoedo, «Parece que hemos vuelto a Bianchini o a Calvi [comentaba el P. Carrillo], pero aquellas eran más recias y pertinaces. Yo las tuve en uno y otro lugar y también en Bolonia» ${ }^{25}$; a fi-

22. Carrillo a Luengo, Mantua, 2 de abril de 1809

23. Carrillo a Luengo, Mantua, 16 de abril de 1809

24. El desarrollo de las fiebres era tal, en todo el entorno mediterráneo, que José Luis Peset sugiere la denominación de «siglo de las fiebres» para el siglo XVIII. Véase PESET, J. L.: «Epidemias y sociedad en la España del fin del Antiguo Régimen», V Congreso Nacional de Historia de la Medicina, Vol. I, Madrid, 1977, p. 46.

25. Carrillo a Luengo, Mantua, 16 de julio de 1809. 
nales de julio ya las sufrían - además de los mencionados-, los padres Calvo, Cordón, Carrera, Miliá, Suers y García. Ya en agosto, el P. Carrillo comenzaba su carta con esta advertencia: «No espere usted por ahora de aquí otras noticias que las propias de un hospital»; a aquellos tercianos se les había unido Zuloaga y Ostiz; en total once de los veintiún jesuitas se encontraban enfermos. Tal era el estado de los prisioneros que se vieron obligados a coger un enfermero para que les ayudara en la atención a los pacientes y en toda la ciudad se había corrido la voz de la infección que aquejaba a la prisión, por lo que las visitas, con las correspondientes donaciones fueron cesando. A finales de mes, sólo dos quedaban sanos. Su única esperanza por entonces era que, a costa de enfermar, se diera cuenta el gobierno de su pernicioso encierro y se propusiera sacarlos de la ciudad. Luengo les recomendaba que, a través del médico que les atendía, instaran a las personas influyentes de Mantua para conseguir algún tipo de remedio, pero en septiembre seguían sin recibir señal alguna que les indicara un cambio en su situación, ni el gobierno de Milán, ni el de Mantua tomaron provisión alguna; además, a principios de otoño, las tercianas aquejaban a gran parte de la población mantuana, por lo que el paseo, que a principios de verano pidieron y les fue denegado, ahora, ya autorizado, se convertía en riesgo de nuevo contagio para los que estaban superando las fiebres.

A principios de julio, la situación parecía que también iba a cambiar en Roma. El P. Luengo describía a Carrillo el susto que habían pasado la noche del 4 al 5 de julio: durante la madrugada habían encarcelado en la casa de los jesuitas a casi un centenar de españoles por causas que se desconocían. Por la tarde, el P. Luengo consiguió entrevistarse con el P. Juan de Arévalo ${ }^{26}$; uno de los jesuitas que residían entonces en el Gesú ${ }^{27}$. Éste le informó de algunas de las personas que habían ido apareciendo esa noche, entre ellas dos prelados españoles, auditores de la Rota ${ }^{28}$; el ayudante del Arzobispo de Toledo, Sebastián Pascual, acompañado del jesuita Faustino Arévalo $^{29}$, Escandón, que había sido tesorero real y el director de la posta española y Ramón Diosdado ${ }^{30}$, que había sido compañero de prisión del P. Luengo. Las sospechas del diarista se centraban en que se había favorecido tal revuelo para desviar la

26. Sobre el P. Arévalo véase: OLAECHEA, R.: «El Cardenal Lorenzana y los ex-jesuitas (Arévalo, Masdeu, Luengo, Bolgeni)», A.H.S.I., LI (1982), pp. 80-160. BATLLORI, M.: «La cultura hispano-italiana de los jesuitas expulsos (1767-1814), Ed. Gredos, Madrid, 1966 y ASTORGANO ABAJO, Antonio: «Encuentro del P. Arévalo con el inquisidor jansenista Nicolás Rodríguez Laso, en la Italia de 1788», El Humanismo extremeño, Real Academia de Extremadura de las Letras y ias Artes, Trujillo, 1998, pp.381-401.

27. «No andan lexos de ciento los jesuitas españoles y portugueses» que residían entonces en el Gesu, LUENGO, M.: Diario, T. XLIII, p. 509.

28. Se refería a Francisco Antonio Javier Bardaquí y a Dionisio Bardaji de Azara, que como el Ministro de España, y el propio P. Luengo, después de tres meses de arresto, habían conseguido la libertad.

29. Faustino Arévalo, que sería rector de la casa de Loyola desde que llegaron en abril de 1816 hasta el verano de 1820 , tampoco había firmado el juramento de fidelidad.

30. El P. Diosdado pertenecía a la Provincia de Toledo, en 1809 quedó detenido en la casa de San Iidefonso junto a otros 6 jesuitas, entre ellos Luengo, por no prestar el juramento. 
atención del auténtico objetivo que tenían los franceses: raptar al Papa. De hecho, pormenorizó la salida del pontífice en su Diario y concluyó con un «le llevan a donde quieren y verisimilmente a Francia. Roma ha quedado atónita» ${ }^{31}$.

La correspondencia procedente de Mantua, desde finales de agosto de 1809, se ciñe a un solo tema: el estado de salud de los presos, y los avances o retrocesos que sufren en sus procesos febriles. El P. Carrillo cae con tercianas a finales de ese verano y en octubre, comienzan a registrarse los primeros fallecimientos: Urteaga murió el 9 de octubre, al día siguiente Encinas, el 14 Isidro Arévalo, el día 16 Zuloaga y el día 21 de ese mismo mes Miliá. Lógicamente, estos fallecimientos, en tan corto espacio de tiempo, tuvieron un considerable impacto en la ciudad, y algunas nobles significativas de Mantua se entrevistaron con el Comandante General de la villa

«y le dijeron que si la intención del gobierno era matarnos, no tenía que hacer más que tenernos un poco mas de tiempo encerrados, hasta que nos acabemos todos de pudrir, pero que si no era essa su intencion era indispensable dejarnos salir para tomar algo de oreo y de exercicio ${ }^{32}$

Así consiguieron permiso para ir a pasear todos los días al huerto botánico, un jardín cerrado próximo al edificio que les servía de prisión. Se destinó un cabo para que les acompañase en el paseo e hiciese la guardia, servicio que tenían que pagar los padres y que consideraban innecesaria ya que, efectivamente, vivían con la puerta abierta y sin escolta desde hacía meses, por lo que si alguno hubiera pretendido escapar lo hubiera hecho a cualquier hora, sin necesidad de que fuera la hora del paseo. La indulgencia fue poco utilizada, comenzaba el frío invierno mantuano con intensas lluvias y además, la mayoría de los presos seguían convalecientes y sin poder moverse de sus catres. El 23 de noviembre moría el P. Ostiz, también de tercianas y el 24 de febrero de 1810 fallecía el P. Roza. El tratamiento seguido -exacto al del resto de los padres- había sido a base de unos polvos que llamaban de Foggia ${ }^{33}$, refiriéndose al nombre del boticario que los fabricaba, pero a partir de los dos primeros meses, tuvieron que recurrir a la quina, medicación que incrementaron hasta enero de 1810 , pues no parecía que remitiera la enfermedad después de casi un año de su aparición, sino que iba trasladándose de unos a otros sin darles tregua.

Las cartas comenzaron a espaciarse a partir de febrero de 1810; a propuesta del $P$. Luengo, decidieron escribirse una vez al mes en lugar de semanalmente, como venía siendo costumbre. Las dificultades económicas que sufrían y los altibajos del pre-

31. LUENGO, M.: Diario, T. XLIII, p. 516.

32. Carrillo a Luengo, Mantua, 5 de noviembre de 1908.

33. A nivel químico, fueron muchos los tratamientos que se aplicaron para enfrentarse a esta enfermedad, uno de ellos fue propuesto por Masdeval y explicado en su obra Relación de las epidemias de calenturas pútridas y malignas.... aparecida en Madrid en 1786. «Propugnaba el uso de lo que denominaba opiata, compuesto a base de tártaro emético y quina», en ALBEROLA ROMÁ, Armando: «Una enfermedad de carácter endémico en el Alicante del XVIII: las fiebres tercianas», Revista de Historia Moderna, Anales de la Univ. de Alicante, $N^{\circ} 5$ (1985), p. 135. 
cio del franqueo, fueron la causa principal de este cambio ${ }^{34}$. Además las circunstancias variaban poco entre los presos de Mantua y las noticias eran escasas y repetitivas, centrándose en el estado de salud de los convalecientes. Al cambiar el periodo de tiempo en que se escribían también cambió el contenido de las misivas ya que condensan los sucesos y aparecen referencias a cuestiones menos cotidianas. En mayo de ese año, el P. Carrillo explicaba al P. Luengo la forma en que se estaba llevando a cabo el Decreto Imperial de supresión en todo el reino de Italia de las religiones y corporaciones eclesiásticas. Política que entraba de lleno en las actuaciones regalistas que se desarrollaron tanto en España como en otros países europeos desde años atrás. La propia expulsión de los jesuitas por parte de Carlos III en 1767 fue el primer fruto de esa política de control estatal del clero y alejamiento de las órdenes regulares de la influencia romana. Por su parte, José II, por un edicto imperial de 1782, suprimió las casas religiosas de varias órdenes y ese mismo año el Emperador promulgó el Reglamento general en torno a la disciplina del clero regular, que debía aplicarse a la Lombardia, y que sería, junto con algunas medidas adoptadas a finales del XVIII por Pombal en Portugal, el máximo exponente de los intereses regalistas ${ }^{35}$.

A finales de noviembre de 1810, apoyándose en la gracia de permiso para volver a sus casas que habían conseguido los jesuitas mayores de sesenta años deportados en Plasencia y Parma, los jesuitas detenidos en Mantua enviaron un Memorial al virrey de Milán para que hiciese llegar al Emperador la súplica de libertad para estos presos de Mantua; se apoyaban en su edad, pues todos superaban los sesenta y algunos los setenta años, las pésimas condiciones de salud que sufrían y las bajas que habían sufrido desde que entraron en la prisión mantuana. El Prefecto mandó la consulta y la respuesta fue negativa, seguirían arrestados hasta que dejaran de resistirse a hacer el juramento acordado. Se quejaban los jesuitas de las carencias que padecían por la falta de pensión, ya que sólo recibían una ayuda del gobierno de Mantua de seis o siete pesos diarios para su manutención, pero «el Emperador dice que a él no le toca el mantenimiento de los jesuitas españoles, sino al rey José» ${ }^{36}$. Esto no se entendía ya que existía un elemento claramente discriminatorio: los jesuitas españoles recibían una escasa pensión, procedente de sus temporalidades en España pero de forma aleatoria. Así, los residentes en Roma cobraban tres pesos duros al mes, los de Bolonia subsistían de limosnas o de los empleos que podían tener, ya que no recibían ayuda

34. «Ayer me llegó carta de Mantua de quatro de este mes [mayo de 1810], y me costó diez y seis bayocos, que hacen tres reales y siete maravedies, quando antes me costaba solamente seis o siete, que no llegan a real y media. No se artan estos grandes hombres de hacernos felices, robandonos y haciendonos mas pobres cada dia.», LUENGO, M.: Diario, T. XLIV, p. 284.

35. A este respecto véase: RODRÍGUEZ LÓPEZ-BREA, C.: «Algunas consideraciones sobre la reforma del clero regular en España (1800-1808)», Espacio, Tiempo y Forma, S.IV, Historia Moderna, t.8 (1995), especialmente, p. 304-305. DÍAZ, F.: Europa: de la llustración a la Revolución, Alianza, Madrid, 1994, pp. 502-504; LABOA, J.: «la estructura eclesiástica durante la época Moderna» Historia de la Iglesia Católica, IV, La época del absolutismo monárquico (1648-1814), Madrid. B.A.C., 1991, pp. 193-259.

36. Carrillo a Luengo, Mantua, 11 de noviembre de 1810. 
de ningún tipo, los presos en Mantua tampoco; luego dependía de no se sabía qué arbitrio que cobrasen o no, según las diferentes legacías donde se encontraran.

El P. Luengo, conocido entre los jesuitas castellanos como «el hermenéutico» por su tendencia a la interpretación -sui generis- de todo escrito que caía en sus manos, hacía notar al P. Carrillo que ese diferente modo de actuar en las legacías italianas también se llevaba a cabo en lo festivo y en lo religioso. De hecho, no dejó de ser sintomático para el diarista el que en Roma se hicieran grandes celebraciones en el aniversario de la coronación en París de Napoleón, mientras en Mantua había pasado la fecha poco menos que desapercibida, y por consiguiente en Milán. De la misma manera los mantuanos no ofrecieron plegaria alguna por el feliz parto de la Emperatriz, mientras en Roma «ordenan con todo empeño que se hagan, instan e insisten en ello, porque pocos tienen gana de hacerlas». Las conclusiones del diarista a este respecto no le dejaban lugar a dudas: los franceses, ausentes de todo tipo de religiosidad, encargaban oraciones en unos sitios y en otros no, dependiendo de la necesidad que tuvieran de que un pueblo en concreto les tuviera por católicos. El hecho de que se hicieran en Roma con tanta pompa respondía, en palabras del P. Luengo:

«..al maligno intento de forzar a los Romanos a reconocer publicamente a Napoleón por su Soverano y en caso de negarse a hacer las dichas oraciones, tener un nuevo pretexto para oprimir a los eclesiasticos» ${ }^{37}$

La actividad docente de los presos mantuanos no declinó mientras las circunstancias se lo permitieron. Hermenegildo Amoedo, a primeros de julio de 1810, solicitó permiso para dar clases a un niño de Mantua por la mañana y por la tarde, y -para sorpresa de toda la comunidad de Mantua-, la policía les informó que todos podían salir mañana y tarde, aunque no tuvieran la autorización oficial del gobierno milanés. Formalidad que prefirieron no solicitar temiendo que se les estrecharan los privilegios de que gozaban. En febrero de 1811, el Ayudante mayor de la Plaza volvió a requerir los servicios de Pedro Cordón para que instruyese a su hijo, labor que había llevado a cabo meses antes. Las lecciones tenían lugar dos veces al día y, algunas tardes, iba con su alumno a pasear a las afuera de la ciudad. De estos privilegios se fueron aprovechando el resto de los jesuitas, aunque nunca recibieron autorización formal de la Policía, quedaba claro que ésta hacía la vista gorda, permaneciendo la prisión poco menos que abierta. El propio P. Carrillo, instruía a un subdiacono «que por la edad podría ser obispo» y bromeaba en sus cartas a Luengo diciéndole que bien podría llamarse a «esta cárcel universidad o Lyceo», dada la labor que acometían. El $P$. Luengo, por el contrario, que no se tomaba en broma ningún asunto relacionado con la Sociedad de Jesús, daba rienda suelta a sus ensoñaciones y escribía: «si en su prisión son buscados para maestros, que haran quando les vean restituidos con honor en sus antiguos colegios? Sera como un tumulto piadoso, no queriendo nadie generalmente en los Estados Catholicos, otros maestros que los jesuitas» ${ }^{38}$

37. LUENGO, M.: Diario, T. XLV, p. 10.

38. LUENGO, M.: Diario, T. XLV, p. 863. 
Las cosas cambiarían substancialmente en Mantua durante los primeros meses de 1812. En febrero se anunció a los trece jesuitas españoles su traslado a Chiari, el fin de su reclusión en la prisión en la que llevaban ya casi cuatro años y la prohibición de salir de la ciudad hasta que se efectuara su desplazamiento. Inmediatamente prepararon un memorial al Prefecto, para que lo enviara al virrey de Milán, en el que argumentaban su avanzada edad y la convalecencia de algunos para evitar un viaje que les sería de gran perjuicio, adjuntaban informes médicos que avalaban el peligro de un posible cambio y añadían el retraso que se derivaría de la venta de las provisiones y ajuares que tenían. El día 26 de febrero llegó un nuevo despacho del Ministro de la Policía general en que se decía «que tendría mucho gusto el Virey en que hiciessemos el juramento de fidelidad al Emperador», advirtiéndoles las ventajas añadidas de las que disfrutarían en caso afirmativo. Firmaron este nuevo juramento al Emperador y esperaron noticias. Pocos días después llegó de Milán una resolución por la que se les permitía continuar libres en Mantua y se les prometía asegurar la misma pensión que cobraban otros jesuitas españoles desterrados en Italia, sin especificarles ni cuánto ni cuándo cobrarían, eso sí, perdieron la asignación de encarcelados que hasta entonces les había permitido subsisitir. No obstante, cuando recogieron sus pertenencias y se dispusieron a salir en busca de hospedaje, recibieron cuarenta napoleones cada uno como «subsidio gracioso» ${ }^{39}$. A principios de mayo de 1812 , recibieron cincuenta ducados como pago de la pensión relativa a los tres primeros meses del año y, desde ese momento, fueron recibiendo la pensión con regularidad durante todo el año. Todos se alojaron con bastante comodidad, el P. Carrillo fue a vivir al Convento de Servitas al que le acompañaron Sandianes, Pedro Cordón y Bouzas.

Sólo hubo una excepción: el P. Gaspar Carrera alegó que siendo español juraba al emperador la fidelidad que puede y debe jurar cualquier extranjero al soberano del país donde habita. Esta puntualización tuvo su inmediata respuesta: el P. Carrera debía ser llevado a una penitenciaría de Mantua, privándosele de los derechos obtenidos por sus compañeros. Se le destinaban tres liras de Milán, como soporte económico para su alimentación, que era lo que habían tenido en la prisión anterior y, en mayo, fue llevado a la cárcel en la que, recientemente, había estado el obispo de Udine. Al cabo de un mes, pidió a Milán Carrera que se le trasladara a otra prisión en la que pudiera decir misa. Se le denegó. Pero como no cesó de enviar instancias, a finales de ese verano se le trasladó a una residencia cercana al convento donde vivía Carrillo, con el permiso de utilizar la capilla para oír y decir misa. Incluso se le permitía pasear por el huerto y por el interior del convento, pero tenía expresamente prohibido poner los pies en la calle.

La reacción del $P$. Luengo al recibir estas noticias era de esperar. Se solidarizaba totalmente con la postura adoptada por Carreras, aunque comprendía que el caso era distinto al que se había dado en Bolonia, ya que en aquella ocasión se les pedía juramento a una constitución que era «contraria a los intereses de la religión» y, en ésta,

39. «Assi rezaba la norma que se nos dio de los recibos», Carrillo a Luengo, Mantua, 25 de abril de 1812. 
sólo se les solicitaba lealtad al gobernante de la nación en la que, por circunstancias ajenas a su voluntad, se encontraban en ese momento. Eso sí, echaba de menos que el P. Carrillo no le hubiera incluido la fórmula del juramento, pero confiaba en la religiosidad y rigurosidad de su «corresponsal en Mantua». Y, aunque continuó la correspondencia con su amigo, en su Diario daba por finalizado el «negocio y causa de los veintiun jesuitas españoles que en Bolonia el fin del año ocho no quisieron ( $y$ ellos solos de dos a tres centenares de españoles) hacer el juramento al Rey de España Joseph Buonaparte y a la Constitución y forma de gobierno de Bayona»"

Manuel Luengo, amigo de etiquetar, diferenciar y encerrar en compartimentos estancos a los desterrados españoles, según el comportamiento que hubiesen llevado durante el exilio, aprovechaba lo ocurrido en Mantua para explicar las diferentes posturas que sobre el asunto del juramento habían adoptado los expulsos. Así estaban los que en Nápoles dieron su palabra al rey José que, posteriormente, fueron tenidos en Roma por napolitanos y evitaron tener que volver a firmar el juramento que se intimó al resto de los españoles en la Ciudad Eterna. Quedaba así establecida, pues, la primera diferencia entre españoles: los «napolitanos» y los «italianos», llamados así por habérseles presentado el juramento en Roma. Pero aún había otra diferencia, esta sí de peso, la de los jesuitas que habían firmado el juramento y la pequeña minoría que se había negado a los primeros los llamaba «Josepinos» o «Bonapartinos» y a los otros, «españoles Nacionales y fernandinos que se conservan con quanto pueden unidos a la Nación». Pero toda esa diversidad de posturas entre los expulsos españoles a la que se refiere el diarista, nunca fue óbice para que sus relaciones fueran entrañables, sin causar, en la práctica, ni la más mínima fisura entre ellos.

Mientras tanto, en Mantua los jesuitas deportados tuvieron que esperar casi dos años para conseguir su libertad incondicional. El día 10 de noviembre de 1813 recibieron carta de la Policía en la que se les comunicaba que quedaban libres para volver a su antiguo lugar de residencia en Bolonia. El que más problemas tuvo fue el $\mathrm{P}$. Carrera, que continuaba preso y que, al ser puesto en libertad, quedó sin subsidio económico y a la espera de que se le concediera la pensión de la que disfrutaban el resto de expresidiarios. El P. Carrillo escribió a su amigo en Roma que el 22 de noviembre se disponían a abandonar Mantua Arascot, Sandianes, Campra, Calvo, García y él mismo. El P. Cordón no hacía planes de vuelta a Bolonia por el momento y prefería quedarse en la ciudad en la que habían vivido los últimos cinco años. En carta de 22 de diciembre de 1813, relata el P. Carrillo a Luengo su viaje desde Mantua a Bolonia, su llegada y recibimiento por los jesuitas españoles que allí quedaron y sus planes de irse a vivir a la casa Fontanelli, que tantos recuerdos traía para ambos, ya que fue una de las primeras que habitaron al llegar a los Estados Pontificios en $1768 \mathrm{y}$, donde ambos enseñaban Teología.

En la Navidad de 1813 fechaba el P. Carrillo la última carta que conservó el P. Luengo; era el final de una correspondencia compuesta por cien cartas de ida a Roma

40. LUENGO, M.: Diario, T. XLVI, p. 192. 
y otras tantas desde la Ciudad Eterna hacia Mantua y Bolonia. La estrecha amistad que mantuvo unidos a los dos jesuitas desde sus días de seminaristas, se quebró en junio de 1814 , cuando el P. Carrillo murió en Bolonia ${ }^{41}$. Fue 1814 un año de especial importancia para los jesuitas, pues no sólo se restituyó la Compañía de Jesús, sino que con la Restauración volvía a imponer la hegemonía de las curias eclesiásticas sobre el poder civil en toda Italia ${ }^{42} y$, en España, Fernando VII permitía el retorno de los expulsos a su patria. El P. Luengo embarcó en el puerto de Civitavecchia con rumbo a España el 7 de noviembre de 1815, el mismo día en que cumplía 80 años de los cuales, 49 habían sido de exilio. También en noviembre, pero un año después, moría en Barcelona.

Su correspondencia tuvo un distinto grado de asiduidad durante los cinco años que duró, fue mucho mayor durante el primero, llegando a enviarse una carta semanalmente; a partir de 1810 las cartas eran ya como máximo dos al mes, por parte de Carrillo y, otras tantas como mínimo de Luengo; a mediados de 1811 se convirtieron en una mensual por ambas partes y fueron más esporádicas a lo largo de 1813, pero no dejaron de mantener contacto hasta poco antes de la muerte del P. Carrillo. El P. Luengo además de compilar todas estas cartas, las organizó cronológicamente, numeró y realizó un índice de ellas en el que insinúa el principal asunto del que trata cada una, formando un cuadernillo que componen más de 250 páginas ${ }^{43}$. La información que ofrecen, junto a los comentarios que sobre esta correspondencia dejó escritos el P. Luengo en su Diario hasta finales de 1813, han sido la base documental de este trabajo.

Estos dos jesuitas dejaron patente que eran conscientes del significado y la trascendencia a sus cartas, superando la relación puramente amistosa para cargar sus misivas de tintes apologéticos. El P. Carrillo, «mi corresponsal en Mantua» como solía Ilamarle el P. Luengo, además de notificar a su íntimo amigo el diarista todos los acontecimientos que se producían entre los prisioneros de Mantua, le enviaba puntual información de las noticias que sobre la Compañía recibía, bien a través de otras cartas, por comentarios personales o aquellas que aparecían publicadas:

«Journal del'Émpire. Esta gazeta puso el dia 13 del mes pasado (diciembre de 1810) bajo el titulo de Indias Orientales la noticia siguiente: Muchos Missioneros del Orden de

41. El P. Luengo dedica dos páginas de su Diario al P. Carrillo cuando conoció su fallecimiento, T. IL, pp. 356-357.

42. «Lo refleja el Código Albertino de 1837 que, por ejemplo, hacía de la apostasía del cristianismo causa legítima para desheredar, mientras que el código penal de 1839 estableció la pena de muerte por la profanación de las hostias consagradas y penas muy graves -que comprendían el exilio o trabajos forzados a perpetuidad-por la blasfemia y la ofensa a lugares sagrados y negaba los derechos civiles a los no católicos» MOLA, Aldo: «Iglesia y Estado en Italia (siglo XIX)», Iglesia, Sociedad y Estado en España, Francia e Italia, Ed. E. La Parra y J. Pradells, Inst. de Cultura «Juan Gil-Albert», Alicante, 1991 , p. 477.

43. Tituló el cuadernillo como «Colección de cartas del P. Juan Joseph Carrillo prisionero en Mantua a su Amigo Manuel Luengo», Colección de Papeles Varios, A.H.L., Escritos de jesuitas del s. XVIII. 
los jesuitas han sido ultimamente acusados de haber conspirado con algunos naturales del pais contra la vida del Emperador de la China...» ${ }^{44}$

Ni que decir tiene que el P. Luengo aprovechaba estos comentarios para incluirlos en su Diario, donde pretendía recopilar toda la lucha que, en su opinión y en la de la mayoría de los expulsos, se estaba fraguando contra la Compañía; además, podemos observar cómo al reproducir los comentarios del P. Carrillo, Luengo los abulta e inclina hacia sus propios fines y los de su escrito: «demostrar la inocencia de la Compañía» y aderezar la historia del destierro de los jesuitas con el ímprobo sufrimiento que padecieron en la persecución de que fueron objeto por sus enemigos: «francmasones, filósofos y jansenistas en general». Mientras el P. Carrillo, más ácido y natural, acentuaba con sorna los aspectos positivos de su encierro, a pesar de las duras circunstancias que padecían.

44. Carrillo a Luengo, Mantua, 17 de enero de 1811. Noticia que desmentiría esta misma gaceta el 7 de febrero de 1811, en Carrillo a Luengo, 10 de marzo de 1811. 


\section{Apéndice}

\section{RESEÑA BIOGRÁFICA DE LOS JESUITAS DETENIDOS EN MANTUA SEGÚN DATOS APARECIDOS EN LOS ESCRITOS DEL P. LUENGO $Y$ EN LA CORRESPONDENCIA MANTENIDA CON ALGUNO DE ELLOS}

Hermenegildo de AMOEDO: Perteneciente a la Provincia de Castilla. Sacerdote y Artista del Colegio de Palencia. Nacido el 10 de abril de 1747 en Pontevedra. Embarcó en el Ferrol el 25 de mayo de 1767 en el «San Juan Nepomuceno», junto al P. Luengo. En Mantua daba clases a niños en distintas familias. Murió en Mantua el 23 de diciembre de 1811.

Mariano ARASCOT: Perteneciente a la Provincia de Aragón y hermano de Felix y de Francisco Arascot, también jesuitas; era estudiante del Colegio de Gandía, en el momento de la expulsión. Se negó a hacer el juramento a José Bonaparte y a la Constitución de Bayona en 1808 por lo que fue deportado a Mantua. Enfermó de tercianas en aquella ciudad, donde se encargaba de las tareas del huerto de la prisión. Fue confesor del obispo de Fano, que visitaba con frecuencia a los jesuitas detenidos. Al morir su hermana en Zaragoza, en el año 1812, heredó parte de su fortuna. Tras serle concedida libertad en noviembre de 1813, llegó a Bolonia a finales de ese año.

Isidro ARÉVALO: Isidro Arévalo nació en Cabezas del Pozo, Ávila, el 15 de mayo de 1745, era el mayor de todos los novicios de Villagarcía y fue su guía en el viaje que les llevó, desde que los separaron de los padres en Torquemada, hasta su reencuentro en Santander, en el mes de mayo de 1767, para salir con ellos hacia el destierro. Escribió en Calvi, una relación de todas las aventuras que pasaron estos novicios de la Provincia de Castilla. Su Relación de lo que pasó con los Novicios de la Compañía de Jesús de la Provincia de Castilla en su expulsión fue uno de los documentos que utilizó el padre Isla para elaborar su Memorial a Carlos III, copiado por Luengo en el tomo II de su Colección de Papeles Curiosos. En 1768, camino del destierro, enfermó y se quedó en Génova para recuperarse; fue uno de los firmantes del Memorial que los novicios enviaron a España solicitando pensión tras la extinción de la Compañía. Murió en Mantua el 14 de octubre de 1809, a la edad de 64 años.

Francisco Javier BOUZAS: Perteneciente a la Provincia de Castilla. Natural de San Esteban de Pedro, Obispado de Santiago, nacido el 22 de abril de 1748. Uno de los novicios que se une en Santander a la Provincia de Castilla; firmante del Memorial que los novicios envían a España solicitando pensión tras la extinción de la Compañía. Residía en Bolonia cuando se negó a firmar el juramento a José Bonaparte y a la Constitución de Bayona en 1808 por lo que fue deportado a Mantua y detenido en aquella ciudad, cuando les fue concedida la libertad para poder regresar a Bolonia a finales de 1813, el P. Bouzas se quedó cuidando a Félix Sebastián. Fue rector del noviciado de Madrid en 1820 , cuando se les intimó la segunda supresión, dio las órdenes pertinentes para cerrar el noviciado, dispensando a los novicios de segundo curso de sus votos de devoción. 
Vicente CALVO: Natural de Iglesario en Galicia, donde nació el 30 de junio de 1745. Fue uno de los novicios que se unió a la Provincia de Castilla en Santander para embarcar hacia Italia; destinado a Indias antes de la expulsión, terminó sus estudios de Filosofía en Bolonia el 24 de septiembre de 1771 con el P. Luengo y firmó el Memorial que los novicios envían a España solicitando pensión tras la extinción de la Compañía en 1773. Residía en Bolonia cuando se negó a firmar el juramento a José Bonaparte y a la Constitución de Bayona en 1808 por lo que fue deportado a Mantua y detenido en aquella ciudad, de la que salió en noviembre de 1813 , cuando les fue concedida la libertad y pudo regresar a Bolonia a finales de ese año.

Joaquín CAMPRA: Terminó sus estudios de Filosofía en septiembre de 1769, siendo alumno del P. Luengo en la casa Bianquini, era natural de Valladolid. Salió hacia España en 1798, residiendo en su ciudad natal donde coincidió, en agosto de ese mismo año, con el P. Luengo. Vivía en Bolonia cuando se negó a firmar el juramento a José Bonaparte y a la Constitución de Bayona en 1808 por lo que fue deportado a Mantua y detenido en aquella ciudad, de la que salió en noviembre de 1813 , cuando les fue concedida la libertad y pudo regresar a Bolonia a finales de ese año.

Gaspar CARRERA: Entró en la Compañía en la Provincia de Andalucía. Perteneciente a la Provincia de Méjico. Fue uno de los que viajaron con Arqueiro destinado a Indias en 1767, sin casi pisar tierra americana, fue desterrado hacia los Estados Pontificios. Se negó a hacer el juramento a José Bonaparte y a la Constitución de Bayona en 1808 por lo que fue llevado y detenido en Mantua. En 1812 se negó a firmar el juramento a Napoleón Bonaparte, alegando que sólo lo haría dejando claro que siendo él español juraba al emperador la fidelidad que puede y debe jurar un extranjero al soberano del país donde vivía, como consecuencia fue detenido, de nuevo, en Mantua. El 10 de noviembre de 1813 se le concedió libertad incondicional y permiso para volver a Bolonia, pero quedó sin subsidio económico y a la espera de que se le concediera la pensión de la que disfrutaban el resto de expresidiarios. A finales de año seguían denegándole el derecho a recibir pensión.

Juan José CARRILLO: Nació el 28 de febrero de 1737 en Ronda, Málaga. Maestro de Lógica en el Colegio de Santiago, perteneciente a la Provincia de Castilla, comparte la casa con Luengo y se quedó enfermo en Calvi; se unió al resto de los expulsos en los Estados Pontificios; impartía Física en la casa Bianchini de Bolonia; salió de esa casa el 26 de septiembre para dirigirse al Colegio de Maestros de Bolonia, pasando antes por las casas de San Juan y por la de Ponzano, siempre en compañíá del P. Luengo, con quien realizó un viaje a Loreto en 1771; fue ayudante del P. Idiaquez en 1773, quien le encargó que escribiera las Quatro moralis: quid facto sit opus jesuitis exulibus, si aut pensioni sit, aut Societati remuntiandum?, con ánimo de remitirlas a Roma. Se negó a firmar el juramento a José Bonaparte y a la Constitución de Bayona en 1808 por lo que fue deportado desde Bolonia a Mantua y detenido en 
aquella ciudad. Mantuvo una extensa correspondencia con Luengo durante los cinco años que duró su prisión. Salió de Mantua el 22 de noviembre de 1813, tras serles intimada la libertad incondicional y regresó a Bolonia. Murió en esa ciudad a finales de junio de 1815 .

Salvador CEA ${ }^{45}$ : Perteneciente a la Provincia de Aragón. Estudiante del Colegio de Teruel y natural de Villanueva de Aranda, en Zaragoza. Nacido el 2 de abril de 1744. Jesuita desde el 16 de junio de 1760. Embarcado en Salou el 1 de mayo de 1767 en el Pingue «Santa Ana». El último trimestre de 1773 residía en Ferrara, donde recibió 375 rls. de pensión ${ }^{46}$. Fue detenido en Bolonia en 1808 por negarse a firmar el juramento a la Constitución de Bayona y enviado preso a Mantua. Allí sufrió tercianas en varias ocasiones. En 1812 firmó el juramento de fidelidad a Napoleón y obtuvo régimen de libertad en la ciudad pero sin consentimiento de abandonarla. Consiguió permiso de Milán para ir un mes a Bolonia, salió el 22 de diciembre de 1812, con ánimo de tramitar su residencia definitiva en Bolonia, y fue muy bien recibido por los jesuitas residentes en aquella ciudad. Finalizado el primer mes, consiguió prórroga de Milán para quedarse otro en Bolonia y en marzo, después de enviar varios memoriales a Milán, adjuntando certificados médicos y recomendaciones, consiguió el permiso de estancia definitiva en Bolonia.

José CORCINES: Fue detenido en Bolonia en 1808 por negarse a firmar el juramento a la Constitución de Bayona y enviado preso a Mantua. Allí sufrió tercianas en varias ocasiones. En 1812 firmó el juramento de fidelidad a Napoleón y obtuvo régimen de libertad en la ciudad pero sin consentimiento de abandonarla.

Pedro CORDóN: Natural de Pipaoma en la Sierra de Cameros. Terminó sus estudios de Filosofía en septiembre de 1769, siendo alumno del P. Luengo en la casa Bianquini; a principios de junio de 1773 se ordenó sacerdote en Bertinoro con el Obispo de aquella ciudad, Francisco $\mathrm{M}^{\mathrm{a}}$ Colombani; escribió el Epigramata in singular coniones Bononia habitas ad modum Reverendo Patre Hicronimo Durazzo Societatis Jesu, in quadragesima anni 1772; cuando estudiaba el tercer año de Teología en la casa Fontanelli de Bolonia. El P. Luengo comentaba, en 1772, que se había publicado una obra de sonetos y canciones del poeta Pedro Cordón, que estaba estudiando su tercer año de Teología en la Casa de Fontanelli, siendo el más joven de toda la Provincia castellana. Por encargo del P. Idiaquez, había ido Cordón componiendo un epigrama de cada uno de los sermones del P. Durazzo, llegando a coleccionar treinta y dos. Fue detenido en Bolonia en 1808 por negarse a firmar el juramento a la Constitución de Bayona y enviado preso a Mantua. Allí dio clases a varios niños de distintas familias. En el verano de 1812, ya en libertad, pero sin permiso para salir del término

45. También aparece como Xea o Gea

46. Datos proporcionados por el profesor Giménez López. 
de Mantua, estuvo en una casa de campo impartiendo primeras letras a jóvenes de una conocida familia, y se le dio permiso para acompañar a Módena a la madre de los niños, cuando éstos tuvieron edad de entrar en internado. En 1813, cuando se concedió permiso a los jesuitas deportados en Mantua para poder volver a Bolonia, el P. Cordón se quedó en Mantua, trabajando como instructor de los niños de una conocida familia mantuana. Cuando murió Zúñiga, Superior de los jesuitas de España tras la restauración de la orden en 1815, el 14 de marzo de 1820 en Madrid, le sucedió el entonces rector de Loyola, Faustino Arévalo, quien, alegando motivos de salud, delegó en Pedro Cordón, quien con el título de sustituto de Viceprovincial debía afrontar los difíciles días de la segunda supresión ${ }^{47}$.

José Antonio ENCINAS: Perteneciente a la Provincia de Méjico. Había sido estudiante del Seminario Real de San Ildefonso de Méjico y nació el 3 de septiembre de 1738. Fue maestro de Gramática en Querétaro, de Teología en el Máximo y maestro de aposentos en San lldefonso en 1767. En Mantua en P. Encinas realizaba funciones de bodeguero desde que les instalaron en aquella prisión. Falleció en esa ciudad el 10 de octubre de 1809 , a los 71 años.

Luis GARCÍA: Perteneciente a la Provincia de Castilla, en 1767 estaba destinado en el Colegio de Palencia y viajó con Luengo en el «San Juan Nepomuceno» desde Ferrol hacia el destierro. Residía en Bolonia cuando se negó a firmar el juramento a José Bonaparte y a la Constitución de Bayona en 1808 por lo que fue deportado a Mantua y detenido en aquella ciudad, de la que salió en noviembre de 1813, cuando les fue concedida la libertad y pudo regresar a Bolonia a finales de ese año.

Manuel MILIÁ: Manuel Miliá pertenecía a la Provincia de Castilla, había nacido el 27 de marzo de 1742 en Tortosa y fue Maestro de Gramática del Colegio de Santander. Residente en Bolonia hasta enero de 1808, murió en Mantua el 21 de octubre de 1809 , a los 67 años.

Martín OSTIZ: Perteneciente a la Provincia de Castilla, era natural de Artica, Navarra, donde nació el 10 de junio de 1730. Fue Maestro de Gramática del Colegio de Bilbao y procurador de su Provincia, encargado de preparar el viaje por los Estados Pontificios de los expulsos que se dirigían a Bolonia. Murió en Mantua el 23 de noviembre de 1809 , a los 79 años.

Pedro RODRÍGUEZ: Perteneciente a la Provincia de Castilla. Natural de Semillas de la Vega, León, donde nació el 28 de abril de 1747. Novicio en Villagarcía de Campos, donde estudiaba el tercer año de Filosofía en 1767, un año antes, el P.

47. Véase sobre Pedro Cordón REVUELTA GONZÁLEZ, M.: «La supresión de la Compañía de Jesús en España en 1820», Razón y Fe, nº 182 (1970), p. 116. 
Luengo había sido su maestro. En Bolonia continuó sus estudios, acabándolos en 1773. Tradujo al español la historia del Pelagismo, escrita por un jesuita francés. Fue arrestado en Bolonia por no querer firmar el juramento a José Bonaparte y a la constitución de Bayona. Llevaba casi tres años detenido en Mantua cuando, el 23 de julio de 1811 murió en aquella prisión, a los 64 años.

Antonio ROZA: Perteneciente a la Provincia de Castilla, fue Maestro de Teología en el Colegio de Segovia, y, una vez desterrados, vivió en la casa Panzano en 1768, donde estaba el Colegio de Teología, un año más tarde pasó a la casa Bianchini donde siguió impartiendo esta doctrina. En 1773 era Maestro de Teología y procurador general de esa casa, sustituyendo al P. Peña. Fue íntimo colaborador del P. Idiaquez, Provincial de Castilla desde poco antes de la extinción, con quien realizó algunas gestiones sobre el encarcelamiento del P. Isla ${ }^{48}$, el P. García, y el P. Ordoñez, sobre el pretendido destierro de esos jesuitas de la ciudad de Bolonia, en 1773, año en el que mantenía una asidua correspondencia con Jaime Andrés. Murió en Mantua el 24 de febrero de 1810 .

Luis SANDIANES: Sacerdote perteneciente a la Provincia de Castilla. Era maestro de menores del Colegio de Monterrey, había nacido en Orense. Embarcó en Ferrol en mayo de 1767 junto al P. Luengo en el «San Juan Nepomuceno». Fue detenido en Bolonia en 1808 por negarse a firmar el juramento a la Constitución de Bayona y enviado preso a Mantua. Allí sufrió tercianas en varias ocasiones. En 1812 firmó el juramento de fidelidad a Napoleón y obtuvo régimen de libertad en la ciudad pero sin consentimiento de abandonarla. Volvió a Bolonia en diciembre de 1813.

Félix SEBASTIÁN: Perteneciente a la Provincia de Méjico. Nacido en diciembre de 1736. Fue detenido en Bolonia en 1808 por negarse a firmar el juramento a la Constitución de Bayona y enviado preso a Mantua. Allí sufrió tercianas en varias ocasiones. En 1812 firmó el juramento de fidelidad a Napoleón y obtuvo régimen de libertad en la ciudad pero sin consentimiento de abandonarla. Volvió a padecer tercianas en agosto de 1813. A finales de ese año intentó volver a Bolonia, cuando les fue concedido permiso a todos los jesuitas que habían sido deportados a Mantua, pero su débil estado de salud se lo impidió.

Joaquín SUERS ${ }^{49}$ : Perteneciente a la Provincia de Andalucía Sacerdote y Maestro de Retórica del Colegio de San Pablo de Granada. Había nacido en Málaga en 1738. Escribió en latín la vida del P. José Morado, que murió en 1769, mientras

48. GIMÉNEZ LÓPEZ, E.: «La apología del jesuitismo en el exilio: el P. Isla en Italia», Disidencias y Exilios en la España Moderna, Actas de la IV Reunión Científica de la Asociación Española de Historia Moderna, Alicante, 27-30 de mayo de 1996, C.A.M., A.E.H.M. y Univ. de Alicante, 1997, pp. $573-$ 608 .

49. También aparece como Sweerts. 
realizada su tercera probación, y tradujo la del P. Salazar escrita por Manuel Valdivia. Murió en Mantua el 31 de enero de 1811, a los 73 años.

Juan Bautista de URTEAGA: Juan Bautista de Urteaga era uno de los estudiantes del P. Luengo en el Colegio de Santiago de Compostela en 1767. Había nacido en Ibarranguela, Vizcaya y terminó sus estudios de Filosofía en septiembre de 1769, todavía como alumno de Luengo y en la casa Bianquini de Bolonia. Murió en Mantua el 9 de octubre de 1809.

Domingo de ZULOAGA: Perteneciente a la Provincia de Castilla, era sacerdote en el Seminario de Villagarcía de Campos. En 1798 volvió a España y tuvo problemas a la entrada por la importante biblioteca que poseía. Se solicitó una ayuda económica a la Corte de Madrid, para que pudiera trasladar los libros a España, a través de Juan María Tineo, sobrino de Jovellanos. Murió en Mantua el 16 de octubre de 1809. 